\title{
Risk factors for hypertension among urban males in Mombasa Kenya
}

By Salehmohamed Juma Suheil MD5 2007/08

\begin{abstract}
:
\end{abstract}
OBJECTIVE

To assess socio-cultural factors associated with hypertension among adult males of Mombasa in Kenya.

\section{MATERIALS AND METHODS:}

A community based cross-sectional study was done in Mombasa Old Town area, whereby males aged 15 yrs and above attending mosque after prayers were randomly requested to participate in the study. Data was collected using structured English questionnaires.

Hypertension (HT) risk factors were assessed, followed by physical examination for obesity anthropometric measurements and blood pressure measurements. Questionnaires were coded and data entered in a computer and analyzed by epi info 2002 statistical computer program.

\section{RESULTS:}

The Prevalence of Hypertension in the population was found to be $6.7 \%$, increase in age and smoking were found to be a predisposing risk factor for HT. Smokers had significant risk ratio of 4 in acquiring $\mathrm{HT}$. It was also noted that Chewing of Miraa and Drinking alcohol had no significant association as a risk predisposing to HT.

Although many alcohol consumers had HT. Occupation was not significantly associated with HT. The study unveiled that physical exercise had protective effect there by decreasing the risk of having HT. High Body Mass index (BMI) and Weight to Hip ration (WHR) was a predisposing risk factor for having HT.

\section{CONCLUSION \& RECOMMENDATIONS}

Doing physical exercise was found to have protective association towards HT. It has been also noted that those people who had hypertension and were on regular medication were relatively better, thus physicians should intervene as early as possible so as to block the natural history of this debilitating disease.

\section{INTRODUCTION}

TheWorld Health Organisation (WHO), classification of blood pressure in adults aged above 18 years is based on the mean of two or more properly measured seated blood pressure readings on two or more office visits'. Normal blood pressure is defined as levels $<120 / 80 \mathrm{mmHg}$. Systolic blood pressure of 120-139 $\mathrm{mmHg}$ or diastolic blood pressure $80-89 \mathrm{mmHg}$ is classified as prehypertension1. These patients are at increased risk of progressing to hypertension.

Hypertension is defined as Systolic blood Pressure above $140 \mathrm{mmHg}$ or Diastolic blood Pressure above $90 \mathrm{mmHg}$ 2. Morethan $95 \%$ of hypertensive patients in the community have essential or idiopathic hypertension and only a small percentage have an identifiable cause hence secondary hypertension ${ }^{3}$. Hypertension is an important risk factor for cardiovascular diseases (CVD).

One of the cornerstones of the primary prevention of cardiovascular diseases has been screening for hypertension and antihypertensive drug treatment ${ }^{3}$. Cardiovascular diseases, most of which are due to atherosclerosis are responsible for nearly $20 \%$ of all deaths world-wide. Principal is the cause of death in all developed countries accounting for $50 \%$ of all deaths and are also emerging as a prominent public health problem in developing countries, ranking third with nearly $16 \%$ of all deaths. Many developing countries are now in a phase of epidemiological transition and face the double burden of communicable and non-communicable diseases, with the severe repercussions this has on their very weak economies ${ }^{3}$. 
There is a rapid development of the 'second wave epidemic' of cardiovascular disease that is now flowing through developing countries. It is now evident from WHO data that coronary heart disease and cerebro-vascular disease are increasing so rapidly that they will rank first and fifth respectively as causes of global health burden by the year 2020.

\section{METHODOLOGY}

A community based cross-sectional study was done among 187 adult male residents of Mombasa in Kenya. The methods involved survey on awareness using a structured questionnaires as well as physical examination on anthropometric measurements and blood pressure. Thus all male population above 15 years had an equal chance of being included in this study.

To investigate the tendency of hypertension to cluster with other cardiovascular risk factors, A risk factor score was used to rank individuals according to the number of other known risk factors for CVD existing at the time of the survey. The following factors and cut-off points were used to build up this risk factor score: 1) $\mathrm{BMI} \geq 25 \mathrm{~kg} / \mathrm{m}^{2}$, 2) current smoker, and 3) physical inactivity (walking or doing some other kind of exercise less than once per week and a self-report of having a sedentary life). The final risk factor score varied from 0 to 3, with 0 meaning no exposure to these factors, 1 being the exposure to any 1 factor and 2 and 3 , being exposure to any combination of 2, 3 or more of these factors, respectively.

Blood pressure (BP) levels were defined as normal when systolic $\mathrm{BP}<140 \mathrm{mmHg}$ and diastolic $\mathrm{BP}<90 \mathrm{mmHg}$. Hypertension was defined as diastolic $B P \geq 90 \mathrm{mmHg}$, or systolic $B P \geq 140 \mathrm{mmHg}$ or current use of antihypertensive medication for management of hypertension, at the time of interview. In case of blood pressure levels below the cutoff points and inconsistencies or missing values regarding indication, additional information was used to classify subjects as hypertensive or nonhypertensive.

Reading of blood pressure was made on the right arm using a standard mercury sphygnomanometer. Three measures were taken after 5 minutes of initial rest and subsequently at 2-minute intervals.
BP was considered as the arithmetic mean of the second and third measurements. Systolic pressure was taken as the level of appearance of the first Korotkoff sounds and diastolic pressure was taken as phase 5 of Korotkoff sounds. Weight was measured in kilograms using a bathroom scale with subjects barefooted and wearing their usual light clothes.

Weight was recorded in Kg. Height was measured in Meters using tape measure with the subject's shoes taken off. Waist and hip circumference was measured by tape measure and ratio calculated. Obesity was measured by the body mass index (BMI) and was classified as overweight (BMl=25.0-29.9 $\left.\mathrm{kg} / \mathrm{m}^{2}\right)$, obese $\left(\mathrm{BMl}=30.0-39.9 \mathrm{~kg} / \mathrm{m}^{2}\right)$ and morbidly obese (BMI $\left.=40.0 \mathrm{~kg} / \mathrm{m}^{2}\right)$. WHR was classified as Low Risk (WHR $\leq$ 0.95), Moderate Risk (WHR=0.96 to 1.0) and High Risk (WHR $\geq 1.0$ ). Smoking was classified as current smokers (number of cigarettes smoked per day), ex-smokers (having stopped at least 6 months before) and non-smokers. Exercise (leisure time) was classified as regular (three or more times per week for at least 20 minutes), irregular (less than three times per week) and no exercise.

Questionnaires were coded and the data was entered in a computer and analyzed by using descriptive statistics, comparison of proportions by the use of chi square test by epi info 2002 statistical computer program.

Ethical clearance to do the study was obtained from the Muhiimbili University of health and allied sciences (MUHAS) directorate of research and publication via the office of the Dean, school of medicine-MUHAS.

Permission to undertake the study among mosque attendees was obtained from the respective mosque leaders. Informed verbal consent was sought before interviewing each respondent.

Confidentiality was highly guaranteed among study participants with anonymity being the standard protocol. All those respondents who were found to be hypertensive (for the 1st time) were counselled and referred for further management to health centres. 


\section{RESULTS}

Out of 180 respondents that were screened for hypertension, 18 (10\%) were found to be hypertensive according to our definition for hypertension.

\section{Fig 1: SMOKING AS A RISK FACTOR FOR} HYPERTENSION

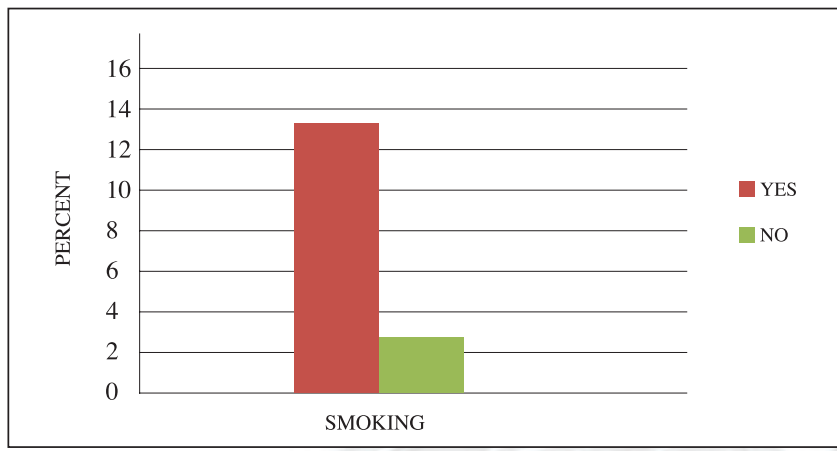

It was found that 9 out of $70(12.9 \%)$ who smoked was diagnosed with hypertension while 3 out of 110 (2.7\%) who did not smoke was diagnosed with hypertension. There was a relative risk (RR) of 4.713 (95\% CI: 1.3125 , 16.8178). This showed that smoking had a significant association as a risk for HT (p-value 0.0100357664).

Fig 2: PROPORTION OF CHEWING MIRAA AS A RISK FACTOR FOR HYPERTENSION.

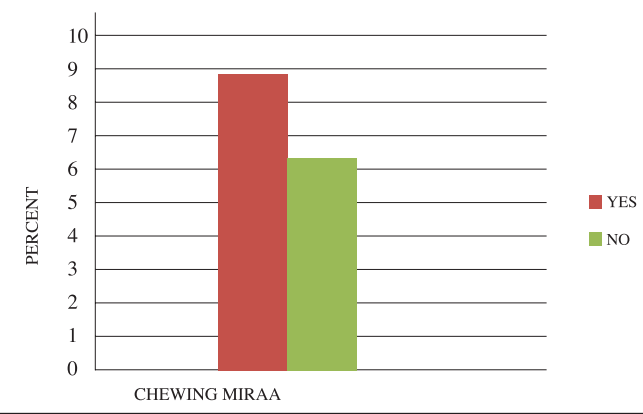

It was found that 3 out 34 respondents who chewed miraa were diagnosed with hypertension, while 9 out of 146 $(6.16 \%)$ who did not chew miraa were diagnosed with hypertension. There was a RR of 1.4314 (95\%CI: 0.4092 - 5.0071).This showed that there was significant risk of getting HT with chewing of miraa.
Fig 3: ASSOCIATION OF PHYSICAL ACTIVITY AS A RISK FACTOR FOR HYPERTENSION.

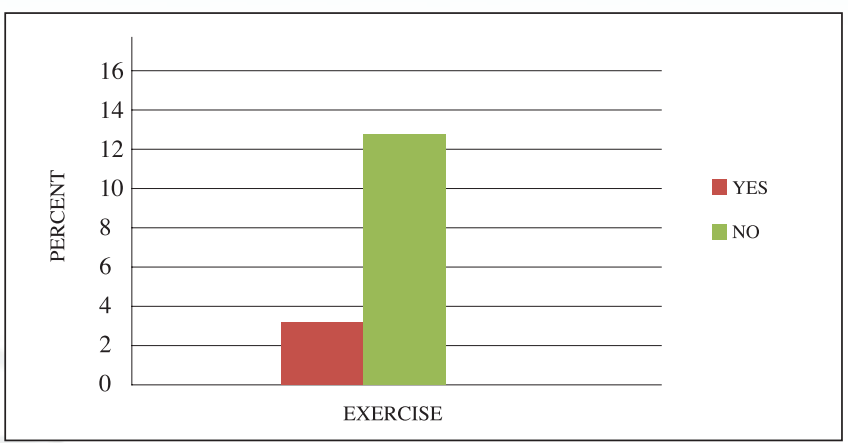

It was found out that 4 out of $117(3.4 \%)$ who did regular exercises were diagnosed with HT while 8 out of 63 $(12.7 \%)$ who did not do any exercise were diagnosed with HT. There was a RR 0.2692 (95\% CI: 0.0844, 0.8593). This showed that there was a protective association between Exercise and HT (p-value 0.0215690257).

Fig 4: ASSOCIATION OF BODY MASS INDEX AS A RISK FACTOR FOR HYPERTENSION (HT)

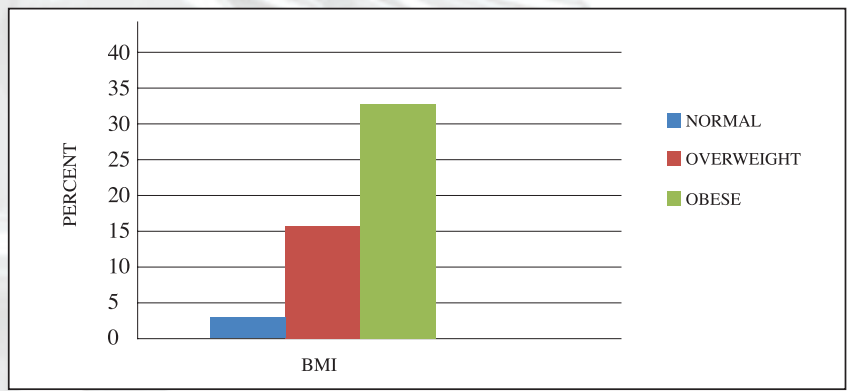

It was found that of those who had normal BMI 3\% were diagnosed to have HT, those who were overweight $15.9 \%$ were diagnosed with HT and those who were obese $33.3 \%$ were diagnosed with HT. This showed that there was a significant association between increase in BMI and risk of developing HT (p-value 0.0006).

Fig 5: ASSOCIATION OF DRINKING ALCOHOL AS A RISK FACTOR FOR HYPERTENSION.

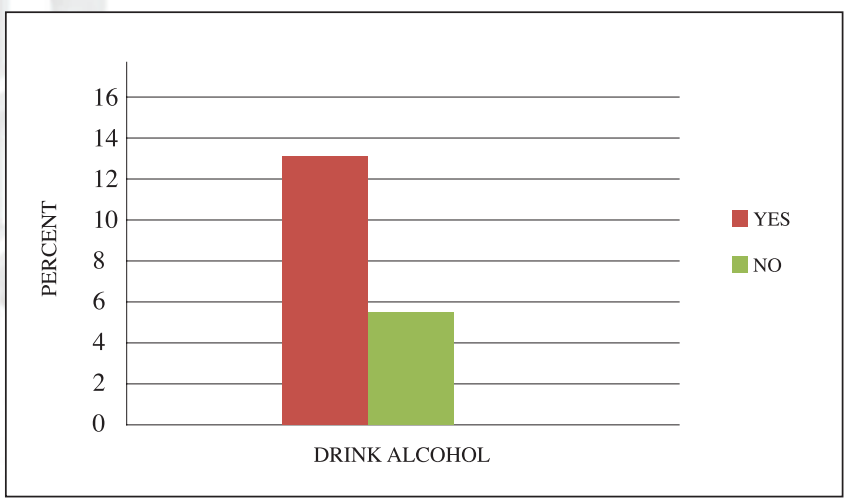

It was found out that $13 \%$ of those who reported to have been taking alcohol had HT while $5.7 \%$ of those who reported to have not been taking alcohol were diagnosed with HT. Thus the risk of developing hypertension was more among alcohol consumers by a factor of 2.3 . 


\section{DISCUSSION}

In this study, it has been found that the prevalence of hypertension among Mombasa residents to have been 10\% (with 8.9\% already on medications). The statistics were found to be significantly lower (6.7\%) when only clinical measurements were performed.

It is more likely that the difference to have been due to effects of medications, in that significant proportions of respondents who were already on medications tend to have blood pressure values that were considered to have been normal.

Also in this study the fact that was an increased number of hypertensives among smokers than not by a factor of four may be used as a clear indicator for explaining the association between smoking and hypertension on exposure-effect basis. This phenomenon is not new in medical literature as perhaps there are more number of studies with similar finding than not. The same phenomenon has been found in the Framingham study ${ }^{4}$, others include the Bambui Health and Ageing study ${ }^{5}$ as well as the population based porto-allegre rrea $^{6}$.

Regular exercise was found to have a protective association with the development of hypertension as revealed by the relative risk of 0.27 in this study. This finding is consistent with several other studies done previously ${ }^{5,6,7}$. Body Mass index (BMI) was found to be a risk factor with the risk increasing as one gets more obese. This finding has been similar to published finding in literature that showed a positive association between obesity and the risk of developing hypertension ${ }^{5,6,7,8}$.

Alcohol taking habit was associated with more than twice the risk of being hypertensive than not in this study. Whether alcohol has a causal factor in the development of hypertension or not is still ill-understood although similar findings have been reported previously $4,5,6$.

\section{CONCLUSION}

Smoking cigarettes, alcohol use, chewing miraa as well as higher Body Mass Index (BMI) was found to be significantly associated with the risk of developing hypertension in this study population. Regular exercise had a protective role as far as the risk of developing hypertension is concerned.

\section{RECOMMENDATIONS}

Health care providers should educate the public on the preventive behaviour towards acquisition of hypertension. More studies are needed on this area to account for the basis of the mentioned risk factors for hypertension found in this study.

\section{ACKNOWLEDGEMENT}

I would like to convey my sincere gratitude to my supervisor Dr. P. Munseri for railing me into the correct rails when I went off track, guidance during the preparation of my study and report writing. My sincere vote of thanks the Muhimbili University of Health And allied sciences for allowing me to carry out this study. Finally, a vote of thanks to the head of the mosques I visited for allowing me to collect data on their premises.

\section{REFERENCES}

5. Chobanian AV et al. Seventh report of the Joint National Committee on prevention,detection, evaluation and treatment of high blood pressure. Hypertension, 2003, 42: 1206-1252.

6. Whelton PK. Epidemiology of hypertension. Lancet. 1994; 344:101-106.

7. Kannel WB. Risk stratification in hypertension: new insights from the Framingham study. Am J Hypertens 2000; 13: 3S-10S

8. Barreto, S. M., V. M. Passos, et al. (2001). "Hypertension and clustering of cardiovascular risk factors in a community in Southeast Brazil--The Bambui Health and Ageing Study." Arq Bras Cardiol 77(6): 576-81.

9. Fuchs FD, Moreira LB, Moraes RS, Bredemeier M, Cardozo SC. Prevalence of systemic arterial hypertension and associated risk factors in the Porto Alegre metropolitan area. Population-based study. Arq Bras Cardiol 1994, 63: 473-479.

10. Wareham NJ, Wong M, Hennings S, et al. Quantifying the association between habitual energy expenditure and blood pressure. Int J Epidemiol 2000; 29: 655-60.

11. Caroline T. M. van Rossum; Hendrike van de Mheen; Jacqueline C. M. Witteman; Albert Hofman; Johan P. Mackenbach; Diederick E. Grobbee. Prevalence, Treatment, and Control of Hypertension by Sociodemographic Factors Among the Dutch Elderly. Am Heart J 2000;35:814. 